\title{
Effect of Mn doping on the microstructure and magnetic properties of $\mathrm{CuFeO}_{2}$ ceramics
}

\author{
Fengjiao YE, Haiyang DAI, Ke PENG, Tao LI, Jing CHEN, \\ Zhenping CHEN ${ }^{*}$, Nannan LI
}

School of Physics and Electronic Engineering, Zhengzhou University of Light Industry, Zhengzhou 450002, China

Received: February 28, 2020; Revised: May 8, 2020; Accepted: May 18, 2020

(C) The Author(s) 2020.

\begin{abstract}
The effects of $\mathrm{Mn}$ doping on the microstructure and magnetic properties of $\mathrm{CuFeO}_{2}$ systems were studied using X-ray diffraction (XRD), X-ray photoelectron spectroscopy, scanning electron microscopy (SEM), and a physical property measurement method. The microstructure measurements demonstrated that the substitution of $\mathrm{Mn}$ for Fe can cause lattice distortion, promote grain growth, and change the valence state of $\mathrm{Fe}$ and $\mathrm{Mn}$ ions. Ceramic samples with doping content $x=0.00-0.03$ exhibited two successive magnetic transition temperature $\left(T_{\mathrm{N}}\right)$ at $T_{\mathrm{N} 1} \approx 14 \mathrm{~K}$ and $T_{\mathrm{N} 2} \approx 10 \mathrm{~K} . T_{\mathrm{N}}$ decreased gradually with the $\mathrm{Mn}^{4+}$ content, and $T_{\mathrm{N} 2}$ was not observed in the $x>0.05$ samples within a temperature range of $T=5-300 \mathrm{~K}$. Magnetic hysteresis loops revealed that only anti-ferromagnetic behavior occurred in the low-doped samples $(x=0.00-0.03)$, and the coexistence of ferromagnetism and anti-ferromagnetism was observed in the high-doped samples $(x=0.05-0.10)$. Besides, the $x=$ 0.10 sample had a maximum magnetization of $5.98 \mathrm{emu} / \mathrm{g}$. This study provides basic experimental data for investigating the relationship between the microstructure and magnetic properties of $\mathrm{CuFeO}_{2}$ systems.
\end{abstract}

Keywords: $\mathrm{CuFeO}_{2}$; ceramics; microstructure; magnetic property

\section{Introduction}

As a delafossite compound, multiferroic $\mathrm{CuFeO}_{2}$ (CFO) has a triangular lattice anti-ferromagnetic (TLA) structure composed of two layers of $\mathrm{O}^{2-}$ and one layer of $\mathrm{Cu}^{+}$along the $c$ axis in crystallography [1,2]. Anti-ferromagnetic interaction between iron ions $(S=$ $5 / 2$ and $L=0$ ) causes geometric frustration $[3,4]$. Without an external magnetic field, the magnetic phase of $\mathrm{CFO}$ changes from a paramagnetic (PM) phase to a

\footnotetext{
* Corresponding author.

E-mail: czhping2007@163.com
}

partially disordered (PD) incommensurate phase at the transition temperature $T_{\mathrm{N} 1}=14 \mathrm{~K}$ with a $R \overline{3} m$ space group lattice structure, and then to a foursublattice (4SL) state at the transition temperature $T_{\mathrm{N} 2}=11 \mathrm{~K}$ with a monoclinic $C 2 / m$ structure. The potential applications, unique magnetic frustrated structures, and physical properties of CFOs have attracted widespread attention. Although in-depth research has been conducted, the magnetic mechanism of CFOs remains elusive $[3,5]$. As reported in many studies, chemical substitution is an effective method for modifying the crystal structure, exchanging interactions between spins, and affecting the magnetic properties of CFO [6-9]. Elkhoun et al. [10] found that 
the partial replacement of $\mathrm{Fe}^{3+}$ with $\mathrm{Sc}^{3+}$ induced spin dilution and anti-ferromagnetic phase transition in CFO systems, causing a dimensional crossover of low-energy anti-ferromagnetic excitation from three-dimensional (3D) to two-dimensional (2D) anti-ferromagnetic interactions. Seki et al. [11] reported that increasing the $\mathrm{Al}^{3+}$ doping concentration significantly improved the ferromagnetism, which was ascribed to the arbitrary distribution of $\mathrm{Al}^{3+}$ in the ferrite hexahedron adjusting the spin structure of CFO systems. Shi et al. [12] reported that $\mathrm{Ga}^{3+}$ substitution in $\mathrm{Fe}^{3+}$ sites weakened the anti-ferromagnetic interactions in CFO systems, obviously shifting $T_{\mathrm{N} 2}$ to lower temperatures and inhibiting the formation of collinear 4SL ground phases at low temperatures.

As a strongly correlated electron system, CFO physical properties are extremely sensitive to strong coupling between electron spins, charges, defects, characteristics, and other microstructures. The substitution of $\mathrm{Mn}^{4+}$ for $\mathrm{Fe}^{3+}$ in CFO systems requires charge compensation, which will influence the creation of cation vacancies and change the system ion valence state, adjusting the effects on the magnetic ground state. Furthermore, replacing $\mathrm{Fe}^{3+}$ with magnetic $\mathrm{Mn}^{4+}$ ions generates mixed-valence ions caused by the charge balance, dilution effect, exchange interaction, and spin inhibition, affecting competition among ions with different magnetic moments that can enrich the CFO system's magnetic properties. However, few studies have reported magnetic ions in CFO systems. Thus, we synthesized Mn-doped CFO via solid-state reactions and studied systematicly using X-ray diffraction (XRD), scanning electron microscopy (SEM), Raman spectroscopy, and physical property measurement. The interplay between the magnetic properties and microstructure was also studied in detail.

\section{Experimental}

$\mathrm{CuFe}_{1-x} \mathrm{Mn}_{x} \mathrm{O}_{2}(x=0,0.01,0.03,0.05$, and 0.10$)$ samples were prepared via solid-state reactions using stoichiometric amounts of $\mathrm{CuO}$ (purity $99.99 \%$ ), $\mathrm{Fe}_{2} \mathrm{O}_{3}$, and $\mathrm{MnO}_{2}$ as reagents. The raw powders in the required proportions were mixed according to their stoichiometric ratios and carefully ground to form a mixture that was calcined at $1123 \mathrm{~K}$ for $12 \mathrm{~h}$ in argon. The mixtures were finely reground and compressed into cylindrical discs of $13 \mathrm{~mm}$ in diameter and
$1.5 \mathrm{~mm}$ in thickness under a hydraulic press with a pressure of $7 \mathrm{MPa}$ and then sintered at $1373 \mathrm{~K}$ for $12 \mathrm{~h}$ in argon. To prevent monovalent $\mathrm{Cu}^{+}$in the CFO system from oxidizing into divalent $\mathrm{Cu}^{2+}$, the calcination and sintering processes were conducted in an argon atmosphere.

The sintered pellets' crystal phases were analyzed via XRD (D8 Advance) with $\mathrm{Cu} \mathrm{K} \alpha$ radiation. X-ray photoelectron spectroscopy (XPS, ESCALAB250Xi) was used to study the specimens' binding energy and ion valence state. The Raman spectra were studied using Renishaw's Raman systems via spectrometry with a $514 \mathrm{~nm}$ Ar laser at room temperature. The fracture morphology was studied via high-resolution SEM (Quanta 250 FEG). The samples' magnetic properties were investigated using a physical property measurement system (PPMS, Quantum Design). The temperature-dependent magnetic susceptibility was tested from 4 to $300 \mathrm{~K}$, and the magnetic hysteresis loops $(M-H)$ at 10 and $13 \mathrm{~K}$ were collected using a vibrating sample magnetometer.

\section{Results and discussion}

\section{1 XRD analysis}

Figure 1(a) shows the powder XRD of the $\mathrm{CuFe}_{1-x} \mathrm{Mn}_{x} \mathrm{O}_{2}$ samples. The doping content $x=0.00-0.03$ phase ceramics have a single hexagonal delafossite structure with a $R \overline{3} m$ space group $\left(\mathrm{CuFeO}_{2}\right.$ ( $\left.\mathrm{PDF} \# 04-007-2807\right)$ ), and some weak diffraction peaks at approximately $38.85^{\circ}, 30.15^{\circ}$, and $56.90^{\circ}$ corresponding to $\mathrm{CuO}$ and $\mathrm{MnO}_{2}$ impurities are observed in the $x=0.10$ samples. This demonstrates that a small amount of Mn doping $(0.00-0.05)$ in the CFO system forms a single-phase structure, but excess doping $(x=0.10)$ can introduce impurities. The amount of $\mathrm{CuO}$ and $\mathrm{MnO}_{2}$ in the $x=$ 0.10 sample indicates that the substitution limitation of $\mathrm{Mn}^{4+}$ ions in the CFO is less than $10 \%$. No traces of manganese oxide or manganate can be observed in the $\mathrm{CuFe}_{1-x} \mathrm{Mn}_{x} \mathrm{O}_{2}$ samples $(x=0-0.05)$, indicating the successful introduction of $\mathrm{Mn}^{4+}$ into the CFO lattice. Rietveld refinement of the XRD data was conducted to obtain the samples' accurate lattice information. The Rietveld refinement of $\mathrm{CuFe}_{0.99} \mathrm{Mn}_{0.01} \mathrm{O}_{2}$ is described in Fig. 1(b). The inset in Fig. 1(a) shows the magnified patterns of the (012) peak. The variations in the samples' peak positions indicate that $\mathrm{Mn}^{4+}$ doping induces a significant lattice distortion, which is also 

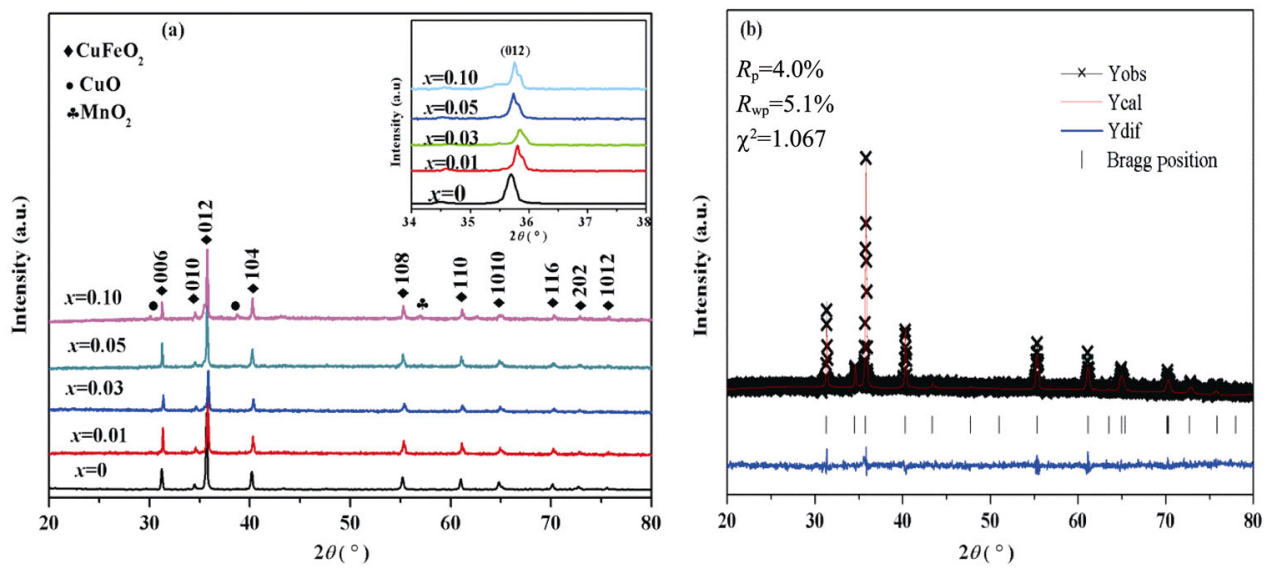

Fig. 1 (a) XRD patterns of the $\mathrm{CuFe}_{1-x} \mathrm{Mn}_{x} \mathrm{O}_{2}(x=0.00-0.10)$ samples. The inset illustrates the expansion of the main peak (012). (b) Rietveld analysis of $\mathrm{CuFe}_{0.99} \mathrm{Mn}_{0.01} \mathrm{O}_{2}$.

confirmed by the calculated lattice parameters in Fig. 2. Figure 2 shows the lattice parameters of $\mathrm{CuFe}_{1-x} \mathrm{Mn}_{x} \mathrm{O}_{2}$ calculated via PowderX software. The lattice parameters $(a$ and $c$ ) slightly decrease with the Mn content from 0 to 0.03 , which is attributed to the smaller cation size of $\mathrm{Mn}^{4+}(0.54 \AA)$ than $\mathrm{Fe}^{3+}(0.64 \AA)$. In the CFO system, the samples' lattice constants are affected by the amount of $\mathrm{Mn}^{4+}$ and stress induced by sintering $[13,14]$. The lattice parameters of the $x=0.05$ sample increase abnormally compared with the $x=0.00-0.03$ samples, which may be ascribed to $\mathrm{Fe}^{2+}(0.76 \AA)$ with a larger ionic radius induced by charge compensation as a competitive advantage. In the $x=0.10$ sample, the lattice parameters decrease compared with the $x=0.05$ sample, which may be due to the decrease in the $\mathrm{Fe}^{2+}$ concentration (as described in the following XPS results). The main diffraction peaks of the $x=0.05$ and $x=0.10$ samples are slightly split, indicating that the delafossite structure of the CFO system with a $R \overline{3} m$ space group may be distorted due to the higher doping

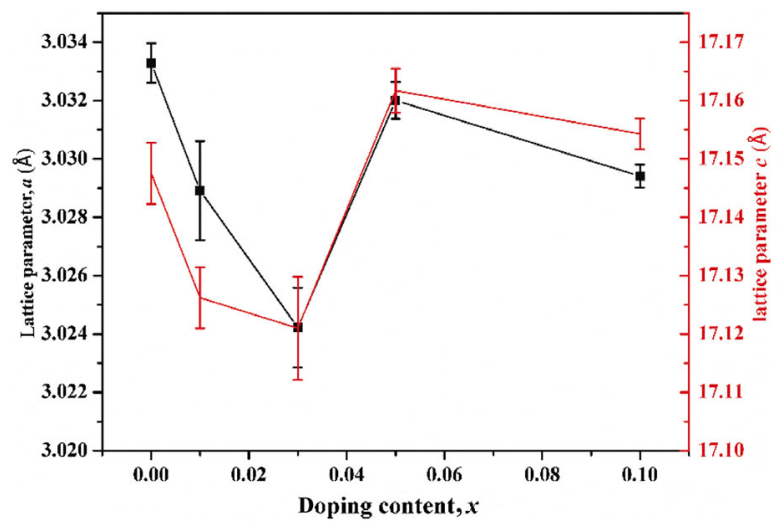

Fig. 2 Lattice parameters $a$ and $c$ of $\mathrm{CuFe}_{1-x} \mathrm{Mn}_{x} \mathrm{O}_{2}$ samples as a function of Mn content $x$. concentration [15-17].

\section{2 XPS analysis}

XPS was used to study the effect of $\mathrm{Mn}^{4+}$ doping on the CFO ceramics' chemical valence. Figure 3 shows the survey spectrum of the undoped sample. To calibrate the binding energy scale, the $\mathrm{C} 1 \mathrm{~s}$ level was assumed to be $284.6 \mathrm{eV}$. The undoped sample's survey spectrum consists of $\mathrm{Cu} 2 \mathrm{p}, \mathrm{Fe} 2 \mathrm{p}, \mathrm{C} 1 \mathrm{~s}$, and $\mathrm{O} 1 \mathrm{~s}$ lines.

Figure 4 shows the fitted XPS spectra of the $\mathrm{Fe} 2 \mathrm{p}_{3 / 2}$ in the $\mathrm{CuFe}_{1-x} \mathrm{Mn}_{x} \mathrm{O}_{2}$ samples. The CFO system's Fe $2 \mathrm{p}_{3 / 2}$ exhibits an asymmetrically broadband, indicating mixed $\mathrm{Fe}$ valence states in the synthesized samples. The Fe $2 p_{3 / 2}$ core level for each spectrum can be divided into two peaks. The peaks located at approximately 710.0 and $712.8 \mathrm{eV}$ correspond to $\mathrm{Fe}^{2+}$ and $\mathrm{Fe}^{3+}$, respectively $[18,19]$. The $\mathrm{Fe}^{2+}$ content is obtained using the ratio of the $\mathrm{Fe}^{2+}$ peak area to the sum of the $\mathrm{Fe}^{2+}$ and $\mathrm{Fe}^{3+}$ peak areas. Figure 5 shows that the

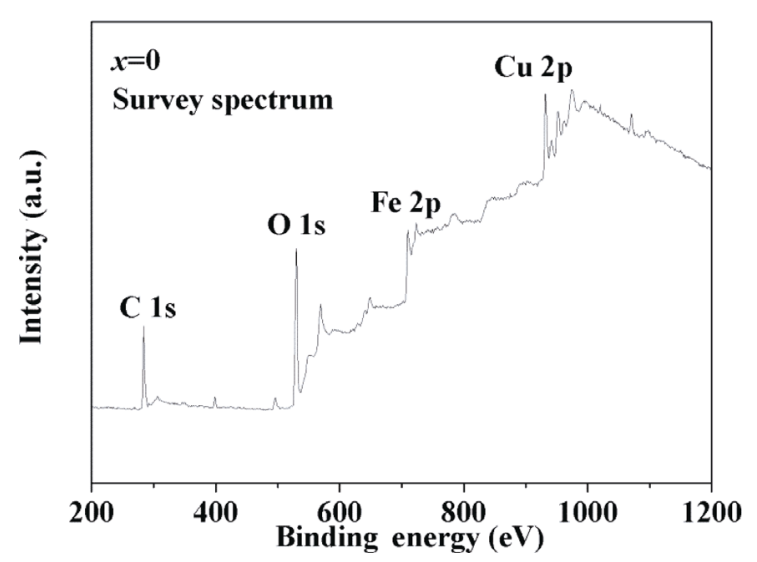

Fig. 3 Survey spectrum of the $x=0$ sample. 


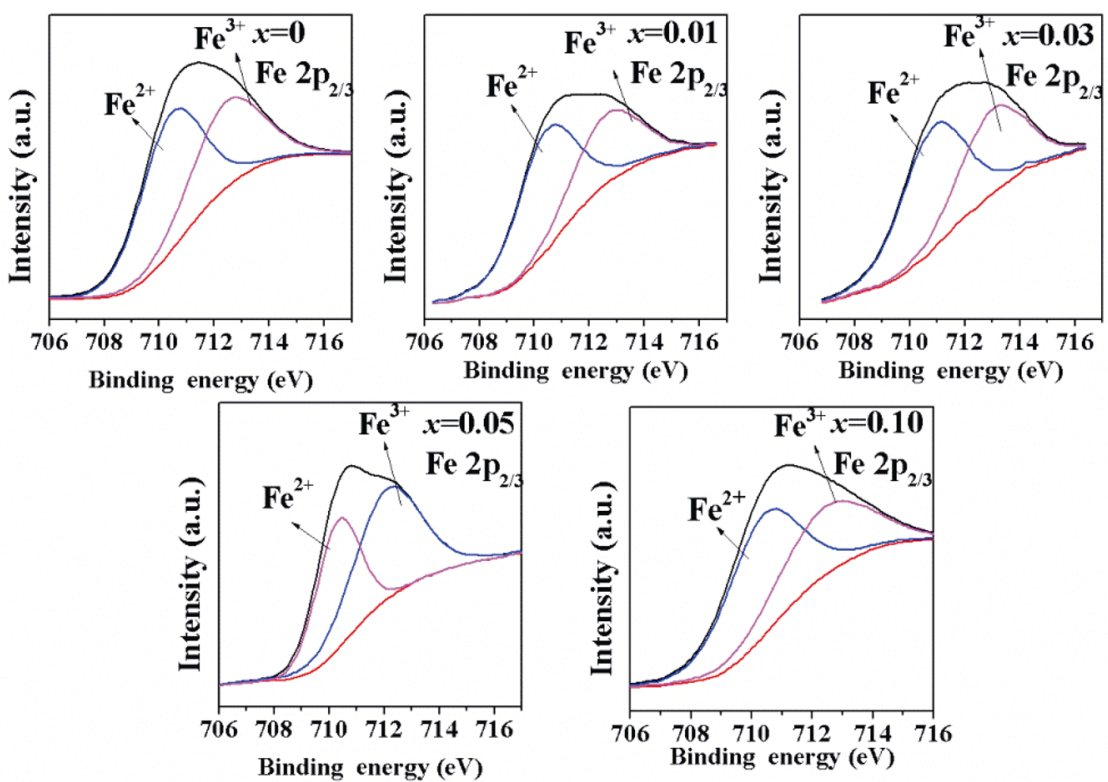

Fig. 4 Fe 2p XPS spectra of the $\mathrm{CuFe}_{1-x} \mathrm{Mn}_{x} \mathrm{O}_{2}$ samples.

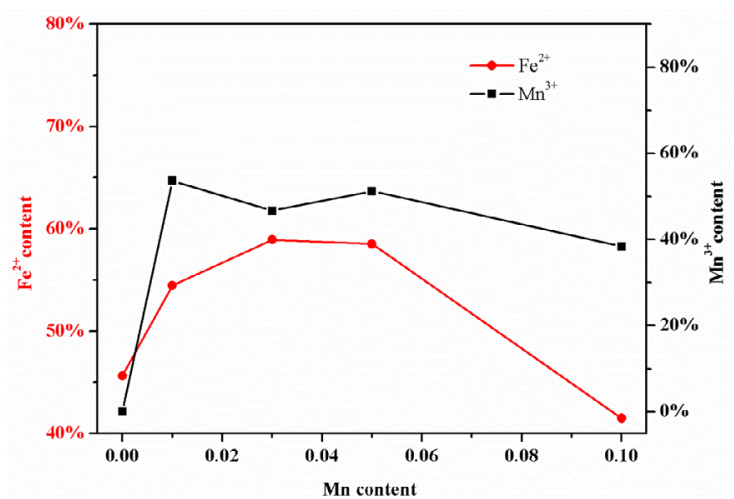

Fig. 5 Amount of $\mathrm{Mn}^{4+}$ and $\mathrm{Fe}^{2+}$ in the $\mathrm{CuFe}_{1-x} \mathrm{Mn}_{x} \mathrm{O}_{2}$ samples.

calculated $\mathrm{Fe}^{2+}$ content is approximately $45.62 \%, 54.45 \%$, $58.92 \%, 58.52 \%$, and $41.48 \%$ for the $x=0.00,0.01$, $0.03,0.05$, and 0.10 samples, respectively. This may be ascribed to the decrease in the oxygen vacancy concentration caused by $\mathrm{Mn}^{4+}$ doping, indicating that the charge neutralization effect caused by $\mathrm{Mn}^{4+}$ doping at the $\mathrm{Fe}$ site can induce a different amount of $\mathrm{Fe}^{2+}$ ions in the CFO system. A similar phenomenon can be observed in other studies [20]. Compared with the $x=$ 0.05 sample, the $\mathrm{Fe}^{2+}$ content in the $x=0.10$ sample decreases, which can be ascribed to the insufficiently reacted $\mathrm{Fe}_{2} \mathrm{O}_{3}$ inside the CFO system increasing the $\mathrm{Fe}^{3+}$ content and then decreasing the $\mathrm{Fe}^{2+}$ content.

The measured Mn 2 $\mathrm{p}_{3 / 2}$ spectrum is depicted in Fig. 6. The Mn $2 p_{3 / 2}$ peak can also be fitted with two peaks. The two peaks represent the $\mathrm{Mn}^{3+}$ (approximately $640.2 \mathrm{eV}$ ) and $\mathrm{Mn}^{4+}$ (approximately $641.5 \mathrm{eV}$ ), respectively. The $\mathrm{Mn}^{3+}$ content can be obtained using the ratio of the $\mathrm{Mn}^{3+}$ peak area to the sum of the $\mathrm{Mn}^{3+}$ and $\mathrm{Mn}^{4+}$ peak areas. The calculated $\mathrm{Mn}^{3+}$ concentrations shown in Fig. 6 show for the $x=0.01,0.03,0.05$, and 0.10 samples are $53.7 \%, 46.7 \%, 51.2 \%$, and $38.4 \%$, respectively. This indicates that the concentration of $\mathrm{Mn}^{3+}$ decreases with the Mn content, which can be ascribed to the charge compensation effect caused by $\mathrm{Mn}^{4+}$ doping that induces the charge balance in the CFO system.

\section{3 Raman spectroscopy}

Figure 7 shows the Raman spectra of the $\mathrm{CuFe}_{1-x} \mathrm{Mn}_{x} \mathrm{O}_{2}$ ceramics. The CFO has a $R \overline{3} \mathrm{~m}$ space group at room temperature and the four atoms in the cell can be characterized with 12 vibration modes $\left(\Gamma=A_{1 \mathrm{~g}}+E_{\mathrm{g}}+\right.$ $3 A_{2 \mathrm{u}}+3 E_{\mathrm{u}}$ ), where $A_{1 \mathrm{~g}}$ and $E_{\mathrm{g}}$ are the vibrations of the $\mathrm{Cu}-\mathrm{O}$ and $\mathrm{Fe}-\mathrm{O}$ bonds, respectively $[6,10,21]$. The samples display two Raman active modes and obey the Horseman selection rule. The peak at approximately $345 \mathrm{~cm}^{-1}$ is the $E_{\mathrm{g}}$ mode and the peak at approximately $678 \mathrm{~cm}^{-1}$ is the $A_{1 \mathrm{~g}}$ mode. The vibration of the two modes correspond to the edge-shared $\mathrm{FeO}_{6}$ octahedron and $\mathrm{O}-\mathrm{Cu}-\mathrm{O}$ linear bond, respectively. $\mathrm{Mn}$ doping induces changes in the peak intensity and the width of $E_{\mathrm{g}}$ and $A_{1 \mathrm{~g}}$ modes in all of the samples. The intensity of the two modes gradually increases with the amount of $\mathrm{Mn}^{4+}$, which is related to the variations in $\mathrm{Fe}-\mathrm{O}$ and $\mathrm{Mn}-\mathrm{O}$ bonding induced by $\mathrm{Mn}$ substitution. It means that $\mathrm{Mn}$ substitution has an obvious effect on the 

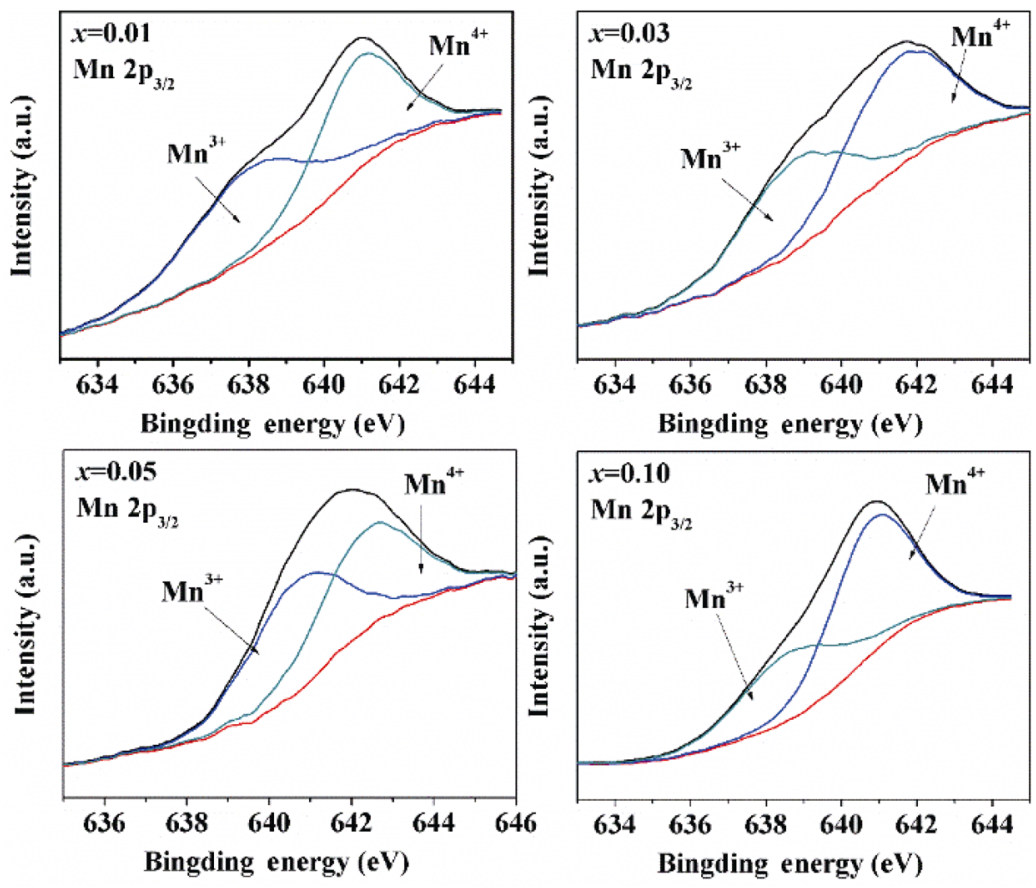

Fig. 6 Mn 2p XPS spectra of the $\mathrm{CuFe}_{1-x} \mathrm{Mn}_{x} \mathrm{O}_{2}$ samples.

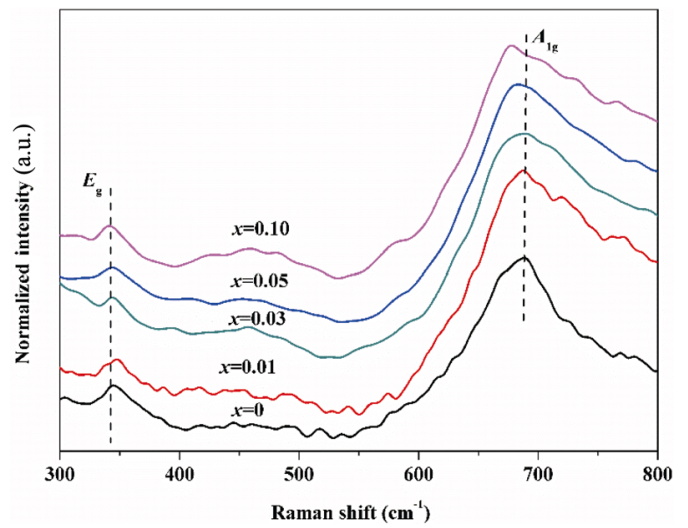

Fig. 7 Raman micrographs of the $\mathrm{CuFe}_{1-x} \mathrm{Mn}_{x} \mathrm{O}_{2}$ samples.

$\mathrm{CuFeO}_{2}$ system's molecular polarizability [10]. The shift in frequency to lower wavenumbers as the amount of $\mathrm{Mn}^{4+}$ doping increases indicates the weakening of the $\mathrm{Fe}-\mathrm{O}$ and $\mathrm{Mn}-\mathrm{O}$ bonds, which is ascribed to the lattice expansion caused by $\mathrm{Mn}^{4+}$ doping (as confirmed by the XRD results). The shift in frequency also indicates that $\mathrm{Mn}$ is successfully introduced into the CFO lattice. A broad peak at approximately $470 \mathrm{~cm}^{-1}$ is observed in the $x=0.03-0.10$ samples, which may be due to the relaxation of the selection rules caused by the $\mathrm{Cu}$ vacancies, interstitial oxygen atoms, or tetrahedrally coordinated $\mathrm{Mn}^{4+} / \mathrm{Fe}^{3+}$ at the $\mathrm{Cu}$ site [22]. Similar phenomena occurred in other reports on CFO systems $[6,20,21]$. Therefore, we confirm that this broad peak is related to defect compensation induced by the charge compensation due to high-valence ion doping.

\section{4 SEM}

Figure 8 shows the microstructural evolution of the fracture surface morphology in the $\mathrm{CuFe}_{1-x} \mathrm{Mn}_{x} \mathrm{O}_{2}(x=$ $0.00-0.10)$ samples. The undoped sample has a dense structure with indistinct grain boundaries and few pores. As the amount of doping increases, the doped samples' grain sizes increase, the grain boundaries are obvious, and the pore sizes increase. This occurs because the cation vacancies induced by $\mathrm{Mn}^{4+}$ doping effectively stimulate the movement of cations, promoting grain growth [23]. Compared with the other samples, the grain of $x=0.05$ sample adhered, the pore volume increases significantly, and some small crystal grains are attached to the large crystal grains. Further increasing the doping concentration, the $x=0.10$ sample exhibits the largest grain sizes and good densification. The largest grain size may be also attributed to the $\mathrm{Cu}$-rich phase $(\mathrm{CuO})$ compounds with a lower melting point (1299 K) [24]. The melting point of CFO is $1443 \mathrm{~K}$ [25], which can promote grain growth [26,27]. The compact fracture morphology in the $x=0.10$ sample could be due to the grown grains occupying the voids. To further study the changes in grain sizes, the samples' grain sizes are calculated by 


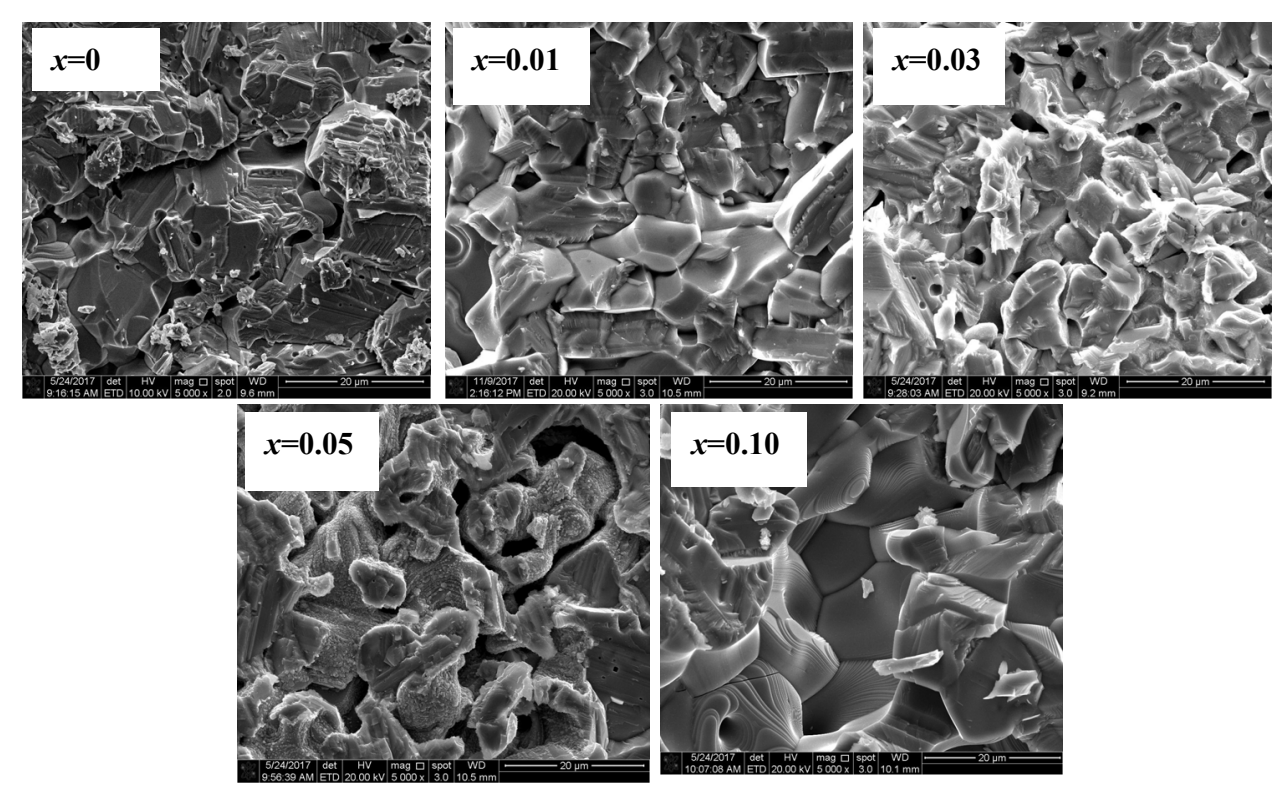

Fig. 8 SEM micrographs of the $\mathrm{CuFe}_{1-x} \mathrm{Mn}_{x} \mathrm{O}_{2}$ samples.

considering the most intense diffraction peak in the XRD pattern using Scherrer's equation:

$$
D=\frac{K \lambda}{\beta \cos \theta}
$$

where $D$ and $\lambda$ are the crystallite size and wavelength of the incident radiation, respectively; $K=0.89 ; \beta$ and $\theta$ are the full width at half maximum in radian and diffraction angle, respectively. The samples' grain size is shown in Table $1 . \mathrm{Mn}^{4+}$ doping induces an increase in the samples' grain size, consistent with the SEM analysis. The $x=0.10$ sample with a grain size of $89.998 \mathrm{~nm}$ is the largest among the $\mathrm{Mn}^{4+}$-doped samples.
Table 1 Lattice parameters, grain size, and the content of $\mathrm{Fe}^{2+}$ and $\mathrm{Mn}^{3+}$ for $\mathrm{CuFe}_{1-x} \mathrm{Mn}_{x} \mathrm{O}_{2}(x=0.00-0.10)$ samples

\begin{tabular}{cccccc}
\hline Mn content & 0 & 0.01 & 0.03 & 0.05 & 0.10 \\
\hline$a(\AA)$ & $3.033(5)$ & $3.028(9)$ & $3.024(4)$ & $3.032(1)$ & $3.029(4)$ \\
$c(\AA)$ & $17.146(3)$ & $17.127(4)$ & $17.122(2)$ & $17.163(3)$ & $17.154(8)$ \\
$D(\mathrm{~nm})$ & $78.177(2)$ & $81.202(1)$ & $80.651(4)$ & $81.191(7)$ & $89.998(2)$ \\
$\mathrm{Fe}^{2+}$ content & $45.62 \%$ & $54.45 \%$ & $58.92 \%$ & $58.52 \%$ & $41.48 \%$ \\
$\mathrm{Mn}^{3+}$ content & 0 & $53.7 \%$ & $46.7 \%$ & $51.2 \%$ & $38.4 \%$ \\
\hline
\end{tabular}

\section{5 Magnetic properties}

Figure 9 presents the plots of the samples' magnetic susceptibility $\chi$ and inverse magnetic susceptibility
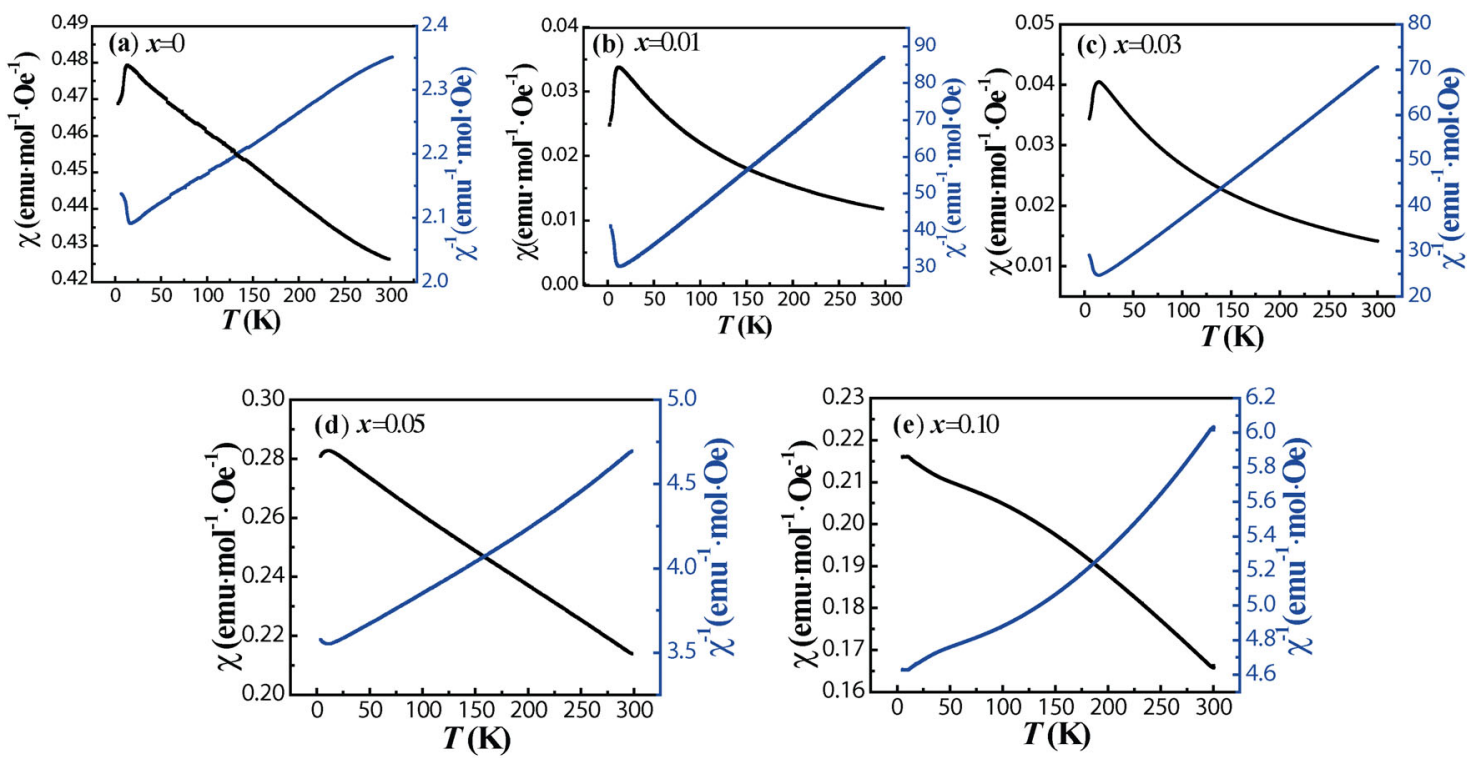

Fig. 9 Temperature dependence of zero-field-cooling susceptibility of the $\mathrm{CuFe}_{1-x} \mathrm{Mn}_{x} \mathrm{O}_{2}$ samples. 
$1 / \chi$ as a function of the temperature in a range of 5$300 \mathrm{~K}$. The samples' $1 / \chi-T$ plots demonstrate a linear relationship at high temperatures, suggesting that the samples have a paramagnetic (PM) state at high temperatures. The $1 / \chi-T$ plots show different non-linear behaviors at low temperatures, possibly due to the appearance of different interactions (antiferromagnetism, ferromagnetism, or ferrimagnetism) at low temperatures. Compared with Refs. [20,22,28,29], different ion-doped CFO series exhibited similar magnetic characteristics in a measured temperature range of $T=5-300 \mathrm{~K}$. Therefore, the doped ion sizes and magnetic properties do not affect the competition between the anti-magnetic and ferromagnetic behaviors in the paramagnetic state in high-temperature and low-temperature regions. To demonstrate the changes in the magnetic transition temperature $\left(T_{\mathrm{N}}\right)$, the samples' $\chi-T$ curves within a narrow temperature range of 5-25 $\mathrm{K}$ are shown in Fig. 9. In the $x=0.00$ 0.03 samples, a broad peak corresponding to magnetic transitions from $\mathrm{PM}$ to collinear incommensurate spin structures occurs at $T_{\mathrm{N} 1} \approx 15 \mathrm{~K}$ and then abruptly decreases, which is associated with the transition to a collinear commensurate spin structure at $T_{\mathrm{N} 2} \approx 11 \mathrm{~K}$ [12]. Figure 10 shows that $T_{\mathrm{N} 1}$ and $T_{\mathrm{N} 2}$ decrease as the Mn content increases from 0.00 to $0.10 . T_{\mathrm{N} 2}$ could not be detected in the $x=0.05-0.10$ samples, which agrees with Refs. $[6,12]$. In the $x=0.10$ sample, $T_{\mathrm{N} 1}$ decreases at approximately $9 \mathrm{~K}$. This evolution of $T_{\mathrm{N} 1}$ and $T_{\mathrm{N} 2}$ could be caused by structural modulation resulting from Mn doping. In general, changes in $T_{\mathrm{N}}$ are ascribed to three factors: the dilution effect, exchange interactions, and release of spin frustration [28]. First, the decrease in $T_{\mathrm{N}}$ induced by the dilution effect [27]

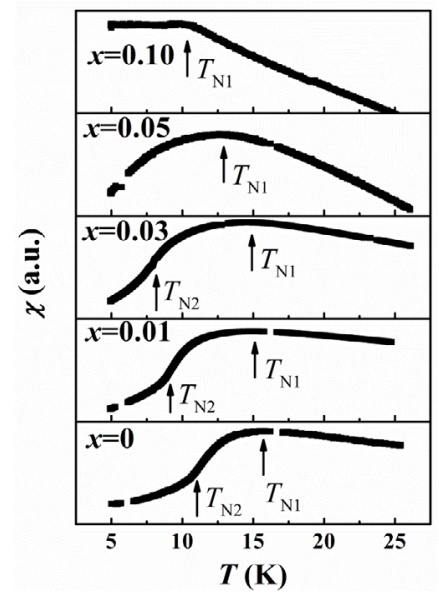

Fig. 10 Expansion of the samples' $\chi-T$ curves in a range of $T=5-25 \mathrm{~K}$. occurs because the magnetism of $\mathrm{Mn}^{4+}$ is lower than that of $\mathrm{Fe}^{3+}\left(\mathrm{Mn}^{4+}\left(m=4 \mu_{\mathrm{B}}\right)\right.$ and $\left.\mathrm{Mn}^{3+}\left(m=5 \mu_{\mathrm{B}}\right)\right)$. Increase in $T_{\mathrm{N} 1}$ is thought to be related to the increase in exchange interactions and partial release of spin frustration [29]. In the $x=0.01$ and 0.03 samples, the exchange interactions may have increased because of the lower lattice parameters than in the undoped samples as demonstrated by the XRD results [30]. In the $x=0.05-0.10$ samples, $T_{\mathrm{N} 1}$ shows the same trend as $0.01 \leqslant x \leqslant 0.03$. Therefore, the dilution effect has the competitive advantage among the three factors in all of the samples.

To clarify the magnetic characteristics near $T_{\mathrm{N}}$, the $M-H$ loops of the $\mathrm{CuFe}_{1-x} \mathrm{Mn}_{x} \mathrm{O}_{2}$ samples were collected. As shown in Fig. 11, the shape of the samples' $M-H$ curves at 10 and $13 \mathrm{~K}$ is similar, demonstrating that the samples display similar magnetic properties. The samples' magnetization is unsaturated under the measured field of 0.5 , indicating the presence of multiple magnetic interactions [31]. The $x=0.00-0.03$ samples' $M-H$ curves exhibit linear field-dependent magnetization, indicating their antiferromagnetic behavior, while the $x=0.05-0.10$ samples demonstrate typical and symmetric hysteresis loop characteristics, indicating the presence of weak CFO-based ferromagnetism due to the short-range $\mathrm{Fe}-\mathrm{O}-\mathrm{Fe}$ interactions induced by $\mathrm{Mn}$ doping $[28,32]$.

As shown in Fig. 11, the magnetization increases with the amount of $\mathrm{Mn}$ in the $\mathrm{CuFe}_{1-x} \mathrm{Mn}_{x} \mathrm{O}_{2}(x=$ $0-0.10)$. The magnetization of $x=0.10$ sample is $5.98 \mathrm{emu} / \mathrm{g}$, almost five times larger than that of the undoped sample (1.21 emu/g). The magnetic properties of CFO ceramics improved by element doping was previously reported by Refs. [11,32,33]. The structure and area of the $M-H$ loop are closely related to the material's particle size, composition, pore size, and cation distribution $[34,35]$. CFOs' magnetic properties are sensitive to the strong coupling between electron spin, charge, and lattice [36]. The samples' different magnetization is attributed to competition between the different magnetic moments of $\mathrm{Fe}^{3+}\left(M=5.9 \mu_{\mathrm{B}}\right)$, $\mathrm{Fe}^{2+}\left(M=5.4 \mu_{\mathrm{B}}\right), \mathrm{Mn}^{4+}\left(M=4 \mu_{\mathrm{B}}\right)$, and $\mathrm{Mn}^{3+}\left(M=5 \mu_{\mathrm{B}}\right)$. Therefore, the amount of ions has a significant impact on a system's magnetic properties. As shown in Fig. 4, as the amount of $\mathrm{Mn}^{4+}$ doping increases, the amount of $\mathrm{Fe}^{3+}$ in the CFO system gradually increases and the amount of $\mathrm{Mn}^{3+}$ gradually decreases, and the amount of $\mathrm{Fe}^{3+}$ gradually increases, improving the CFO system's magnetic properties. Increasing the amount of $\mathrm{Mn}^{3+}$ 

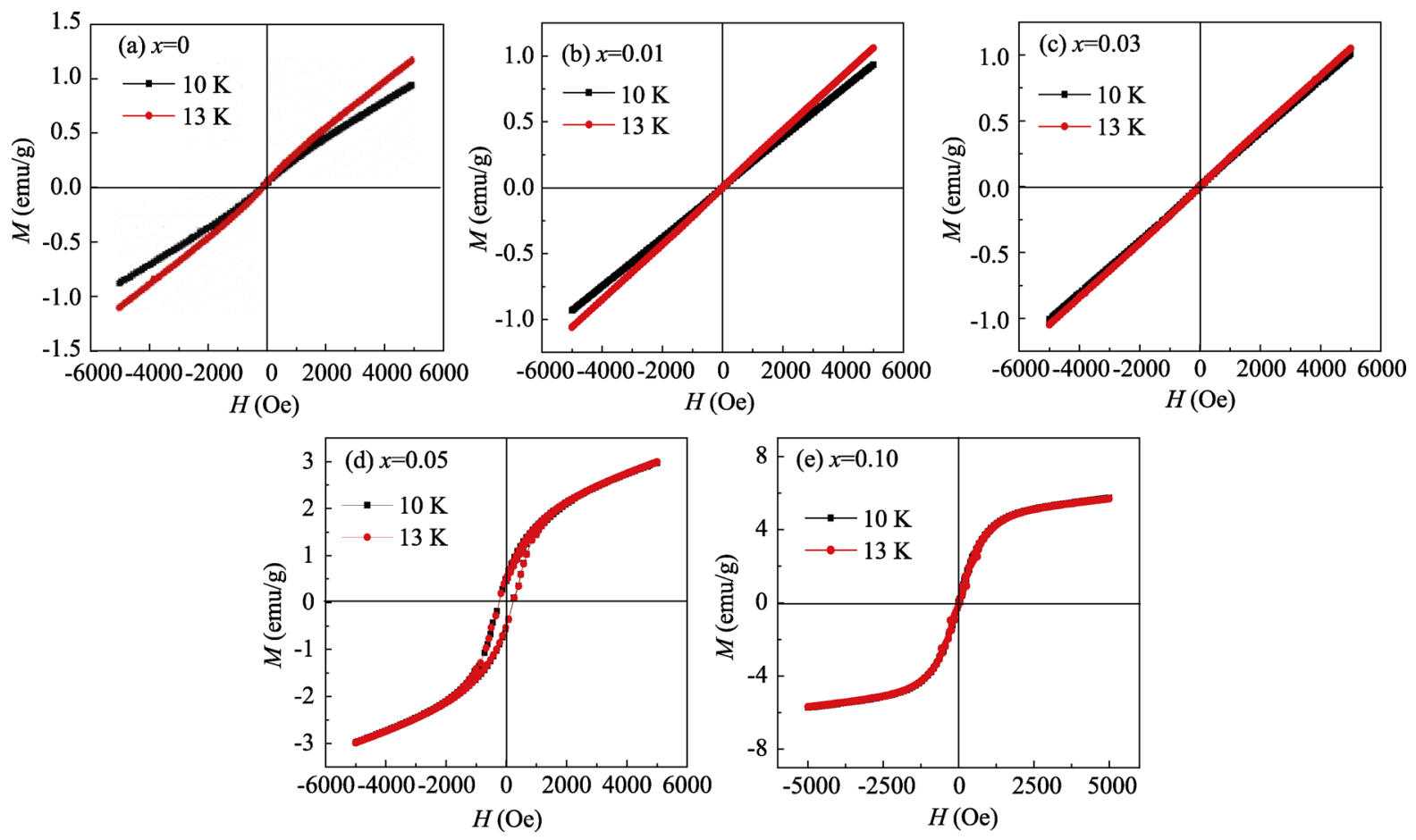

Fig. $11 M-H$ loops of the $\mathrm{CuFe}_{1-x} \mathrm{Mn}_{x} \mathrm{O}_{2}$ samples.

inhibits the CFO system's magnetic properties [37,38]. Therefore, in CFO systems, competition occurs between various magnetic moments and ionic magnetism. For example, the $x=0.10$ sample has a maximum magnetization of $5.3 \mathrm{emu} / \mathrm{g}$, and the amount of $\mathrm{Fe}^{3+}$ is greater than in the other samples. Thus, the improvement in magnetization can be elucidated based on the following factors: (1) Increasing the grain size and amount of Mn causes deformation in the magnetic spin structure, improving the CFO's magnetic properties; (2) the charge compensation induced by the substitution of tetravalent $\mathrm{Mn}$ by trivalent $\mathrm{Fe}$ causes cationic vacancies. The anti-parallel spin ordering in CFOs may be affected by vacancies, improving their magnetic properties; (3) the substitution of Fe by Mn in CFOs can change the bond lengths and angles, changing the inclination angle of $\mathrm{FeO}_{6}$ octahedron, which modulates the system's magnetic spin and improves the magnetic properties; (4) the greater the $\mathrm{Fe}^{3+}$ ion content, the greater the magnetization. Compared with the studies on Ti-doped CFO [32], in cases of the same valence ion substitution, the magnetic structure deformation caused by small-size ion doping, and the competitive effect among ions of different magnetic moments is more significantly conducive to improving the magnetic properties of CFO systems. In conclusion, changes in the microstructures, grain sizes, charge compensation, and magnetic moments of different ions are important factors affecting the magnetic properties of CFO systems.

\section{Conclusions}

CFO samples were prepared via solid-state reactions, and the effects of $\mathrm{Mn}$-doped $\mathrm{CuFeO}_{2}$ on the structures and magnetic properties were investigated. The microstructure results demonstrated that $\mathrm{Mn}$ doping caused obvious changes in the lattice parameters and high $\mathrm{Mn}$ concentration damaged the single-phase structure in the CFO system. The SEM results showed that the average grain size increased due to $\mathrm{Mn}$ doping. The $x=0.1$ sample had a denser microstructure, larger grains, and more distinct grain boundaries than other samples. The Raman spectroscopy results demonstrated that $\mathrm{Mn}^{4+}$ successfully entered the CFO's crystal lattice and $\mathrm{Mn}$ substitution affected the variations in $\mathrm{Fe}-\mathrm{O}$ and $\mathrm{Mn}-\mathrm{O}$ bonding and had an obvious effect on the deformation of the $\mathrm{CuFeO}_{2}$ system's molecular polarizability. The magnetic measurements showed that the anti-ferromagnetic $T_{\mathrm{N}}$ gradually decreased as the amount of $\mathrm{Mn}$ decreased. However, in the $x=$ $0.05-0.10$ samples, $T_{\mathrm{N} 2}$ could not be detected within the tested temperature range. The $M-H$ curves 
demonstrated that the $x=0.00-0.03$ samples exhibited the highest anti-ferromagnetic behavior, and the $x=$ 0.05-0.10 samples had weak ferromagnetism. The $x=$ 0.10 sample had the highest magnetization compared with other samples. The improvement in ferromagnetism induced by $\mathrm{Mn}$ doping can be attributed to the size effects, structural distortion, charge compensation effects, and magnetic moments of the different ions.

\section{Acknowledgements}

This study was supported by the National Natural Science Foundation of China (11675149 and 11775192).

\section{References}

[1] Chatterjee BK, Dey A, Ghosh CK, Chattopadhyay KK. Interplay of bulk and surface on the magnetic properties of low temperature synthesized nanocrystalline cubic $\mathrm{Cu}_{1-x} \mathrm{Zn}_{x} \mathrm{Fe}_{2} \mathrm{O}_{4}$ ( $x=0.00,0.02,0.04$ and 0.08). J Magn Magn Mater 2014, 367: 19-32.

[2] Tamatsukuri H, Mitsuda S, Nakamura $\mathrm{T}$, et al. Spin-lattice-coupling-mediated magnetoferroelectric phase transition induced by uniaxial pressure in multiferroic $\mathrm{CuFe}_{1-x} \mathrm{M}_{x} \mathrm{O}_{2}$ (M=Ga, Al). Phys Rev B 2017, 95: 174108.

[3] Nakajima T, Mitsuda S, Haraldsen JT, et al. Magnetic interactions in the multiferroic phase of $\mathrm{CuFe}_{1-x} \mathrm{Ga}_{x} \mathrm{O}_{2}(x=$ $0.035)$ refined by inelastic neutron scattering with uniaxial-pressure control of domain structure. Phys Rev B 2012, 85: 144405 .

[4] Dai C, Tian XK, Nie YL, et al. Surface facet of $\mathrm{CuFeO}_{2}$ nanocatalyst: A key parameter for $\mathrm{H}_{2} \mathrm{O}_{2}$ activation in Fenton-like reaction and organic pollutant degradation. Environ Sci Technol 2018, 52: 6518-6525.

[5] Ye F, Fernandez-Baca JA, Fishman RS, et al. Magnetic interactions in the geometrically frustrated triangular lattice AntiferromagnetCuFeO $\mathrm{C}_{2}$. Phys Rev Lett 2007, 99: 157201.

[6] Elkhouni T, Amami M, Colin CV, et al. Structural and magnetoelectric interactions of $(\mathrm{Ca}, \mathrm{Mg})$-doped polycrystalline multiferroic $\mathrm{CuFeO}_{2}$. Mater Res Bull 2014, 53: 151-157.

[7] Kundys B, Maignan A, Pelloquin D, et al. Magnetoelectric interactions in polycrystalline multiferroic antiferromagnets $\mathrm{CuFe}_{1-x} \mathrm{Rh}_{x} \mathrm{O}_{2}(x=0.00$ and $x=0.05)$. Solid State Sci 2009, 11: 1035-1039.

[8] Wei M, Xia ZC, Yang F, et al. Influence of nonmagnetic Ga ions on the magnetoelectric coupling in $\mathrm{CuFe}_{1-x} \mathrm{Ga}_{x} \mathrm{O}_{2}$. $J$ Phys D: Appl Phys 2018, 51: 265001.

[9] Ozkendir OM. Crystal and electronic study of neodymiumsubstituted $\mathrm{CuFeO}_{2}$ oxide. Metall Mater Trans A 2016, 47: 2906-2913.

[10] Elkhoun T, Amami M, Hlil EK, et al. Effect of spin dilution on the magnetic state of delafossite $\mathrm{CuFeO}_{2}$ with an $S=5 / 2$ antiferromagnetic triangular sublattice. $J$ Supercond Nov Magn 2015, 28: 1439-1447.

[11] Seki S, Yamasaki Y, Shiomi Y, et al. Impurity-dopinginduced ferroelectricity in the frustrated antiferromagnetCuFeO 2 . Phys Rev B 2007, 75: 100403.

[12] Shi LR, Jin Z, Chen BR, et al. Unusual doping effect of non-magnetic ion on magnetic properties of $\mathrm{CuFe}_{1-x} \mathrm{Ga}_{x} \mathrm{O}_{2}$. J Magn Magn Mater 2014, 372: 7-11.

[13] Deng ZH, Fang XD, Wu SZ, et al. Structure and optoelectronic properties of $\mathrm{Mg}$-doped $\mathrm{CuFeO}_{2}$ thin films prepared by sol-gel method. J Alloys Compd 2013, 577: 658-662.

[14] Jiang HF, Zhu XB, Lei HC, et al. Effects of Mg substitution on the structural, optical, and electrical properties of $\mathrm{CuAlO}_{2}$ thin films. J Alloys Compd 2011, 509: 1768-1773.

[15] Li YT, Zhang HG, Dong XG, et al. The study of electronic structures for $\mathrm{Bi}_{0.95} \mathrm{R}_{0.05} \mathrm{FeO}_{3}(\mathrm{R}=\mathrm{Ce}, \mathrm{Eu}, \mathrm{Er})$ multiferroic material. J Electron Spectrosc Relat Phenom 2014, 196: 121-124.

[16] Pellicer-Porres J, Segura A, Ferrer-Roca C, et al. Structural evolution of the $\mathrm{CuGaO}_{2}$ delafossite under high pressure. Phys Rev B 2004, 69: 024109.

[17] Makhdoom AR, Akhtar MJ, Rafiq MA, et al. Investigation of transport behavior in $\mathrm{Ba}$ doped $\mathrm{BiFeO}_{3}$. Ceram Int 2012, 38: $3829-3834$.

[18] Arya G, Yogiraj J, Negi NS, et al. Observation of enhanced multiferroic, magnetoelectric and photocatalytic properties in $\mathrm{Sm}-\mathrm{Co}$ codoped $\mathrm{BiFeO}_{3}$ nanoparticles. J Alloys Compd 2017, 723: 983-994.

[19] Gu YH, Zhao JG, Zhang WY, et al. Improved ferromagnetism and ferroelectricity of $\mathrm{La}$ and $\mathrm{Co}$ co-doped $\mathrm{BiFeO}_{3}$ ceramics with Fe vacancies. Ceram Int 2016, 42: 8863-8868.

[20] Dai HY, Ye FJ, Li T, et al. Studies on the microstructure and magnetic properties of $\mathrm{Cu}_{0.97} \mathrm{~A}_{0.03} \mathrm{FeO}_{2}(\mathrm{~A}=\mathrm{Ca}, \mathrm{Sr}, \mathrm{Ba})$ ceramics. J Magn Magn Mater 2020, 498: 166082.

[21] Elkhouni T, Amami M, Strobel P, et al. Effect of $\mathrm{Zn}$ substitution on the structural and physical properties of delafossite-type oxide $\mathrm{CuCrO}_{2}$. J Supercond Nov Magn 2014, 27: 1111-1118.

[22] Dai HY, Xie XY, Chen ZP, et al. Microstructure evolution and magnetic properties of $\mathrm{Eu}$ doped $\mathrm{CuFeO}_{2}$ multiferroic ceramics studied by positron annihilation. Ceram Int 2018, 44: 13894-13900.

[23] Bhushan B, Basumallick A, Bandopadhyay SK, et al. Effect of alkaline earth metal doping on thermal, optical, magnetic and dielectric properties of $\mathrm{BiFeO}_{3}$ nanoparticles. J Phys D: Appl Phys 2009, 42: 065004.

[24] Zhang WQ, Sun CW. Effects of $\mathrm{CuO}$ on the microstructure and electrochemical properties of garnet-type $\mathrm{Li}_{6.3} \mathrm{La}_{3} \mathrm{Zr}_{1.65} \mathrm{~W}_{0.35} \mathrm{O}_{12}$ solid electrolyte. J Phys Chem Solids 2019, 135: 109080.

[25] Zhang L, Tan XJ, Xiong DK, et al. Study of the effect of synthetic procedure on microstructure, defects and magnetism of multiferroic $\mathrm{CuFeO}_{2}$ ceramics. Appl Phys A 2018, 124: 353. 
[26] Li T, He HF, Zhang $\mathrm{T}$, et al. Effect of synthesizing temperatures on the microstructure and electrical property of $\mathrm{CaCu}_{3} \mathrm{Ti}_{4} \mathrm{O}_{12}$ ceramics prepared by Sol-gel process. $J$ Alloys Compd 2016, 684: 315-321.

[27] Hutagalung SD, Ooi LY, Ahmad ZA. Improvement in dielectric properties of $\mathrm{Zn}$-doped $\mathrm{CaCu}_{3} \mathrm{Ti}_{4} \mathrm{O}_{12}$ electroceramics prepared by modified mechanical alloying technique. $J$ Alloys Compd 2009, 476: 477-481.

[28] Hutagalung SD, Ooi LY, Ahmad ZA. Improvement in dielectric properties of $\mathrm{Zn}$-doped $\mathrm{CaCu}_{3} \mathrm{Ti}_{4} \mathrm{O}_{12}$ electroceramics prepared by modified mechanical alloying technique. $J$ Alloys Compd 2009, 476: 477-481.

[29] Liu DW, Gu LT, Chen ZP, et al. Structural, magnetic, and giant dielectric properties of $\mathrm{Gd}$ substituted $\mathrm{CuFeO}_{2}$ composites. J Supercond Nov Magn 2019, 32: 2923-2929.

[30] Elkhoun T, Amami M, Hlil EK, et al. Effect of spin dilution on the magnetic state of delafossite $\mathrm{CuFeO}_{2}$ with an $S=5 / 2$ antiferromagnetic triangular sublattice. $J$ Supercond Nov Magn 2015, 28: 1439-1447.

[31] Hayashi K, Fukatsu R, Nozaki T, et al. Structural, magnetic, and ferroelectric properties of $\mathrm{CuFe}_{1-x} \mathrm{Mn}_{x} \mathrm{O}_{2}$. Phys Rev $B$ 2013, 87: 064418.

[32] Yadagiri K, Nithya R, Shukla N, et al. Effects of Dy sub lattice dilution on transport and magnetic properties in $\mathrm{Dy}_{1-x} \mathrm{~K}_{x} \mathrm{MnO}_{3}$. AIP Adv 2017, 7: 035003.

[33] Dai HY, Gu LT, Li T, et al. Investigations of Ti-substituted $\mathrm{CuFeO}_{2}$ ceramics on the structure, defects, the local electron density and magnetic properties. J Magn Magn Mater 2019, 484: 279-285.

[34] Shisode MV, Kounsalye JS, Humbe AV, et al. Investigations of magnetic and ferroelectric properties of multiferroic Sr-doped bismuth ferrite. Appl Phys A 2018, 124: 603.
[35] Dai HY, Xue RZ, Chen ZP, et al. Effect of Eu, Ti co-doping on the structural and multiferroic properties of $\mathrm{BiFeO}_{3}$ ceramics. Ceram Int 2014, 40: 15617-15622.

[36] Yasmin N, Abdulsatar S, Hashim M, et al. Structural and magnetic studies of $\mathrm{Ce}-\mathrm{Mn}$ doped $\mathrm{M}$-type $\mathrm{SrFe}_{12} \mathrm{O}_{19}$ hexagonal ferrites by sol-gel auto-combustion method. $J$ Magn Magn Mater 2019, 473: 464-469.

[37] Zhang L, Goodman BA, Xiong DK, et al. Evolution of microstructure, optical, and magnetic properties in multiferroic $\mathrm{CuFe}_{1-x} \mathrm{Sn}_{x} \mathrm{O}_{2}(x=0-0.05)$. Ceram Int 2019, 45: 3007-3012.

[38] Dong GH, Tan GQ, Luo YY, et al. Structural transformation and multiferroic properties of single-phase $\mathrm{Bi}_{0.89} \mathrm{~Tb}_{0.11} \mathrm{Fe}_{1-x} \mathrm{Mn}_{x} \mathrm{O}_{3}$ thin films. Appl Surf Sci 2014, 290: 280-286.

[39] Quan CY, Han YM, Gao N, et al. Comparative studies of pure, $\mathrm{Ca}$-doped, Co-doped and co-doped $\mathrm{BiFeO}_{3}$ nanoparticles. Ceram Int 2016, 42: 537-544.

Open Access This article is licensed under a Creative Commons Attribution 4.0 International License, which permits use, sharing, adaptation, distribution and reproduction in any medium or format, as long as you give appropriate credit to the original author(s) and the source, provide a link to the Creative Commons licence, and indicate if changes were made.

The images or other third party material in this article are included in the article's Creative Commons licence, unless indicated otherwise in a credit line to the material. If material is not included in the article's Creative Commons licence and your intended use is not permitted by statutory regulation or exceeds the permitted use, you will need to obtain permission directly from the copyright holder.

To view a copy of this licence, visit http://creativecommons. org/licenses/by/4.0/. 